\title{
Case of Progressive/Relapsed Multiple Myeloma presenting with Primary Lesion in the Mandible
}

\author{
Dr. Pallavi Saxena", Dr. Naiem Ahmed, Dr. Kusum Singh \\ Department of Dentistry, Sardar Patel Medical College and Associated Hospitals Bikaner, Rajasthan, India
}

DOI: $10.36348 /$ sjodr.2020.v05i07.009 $\quad$ | Received: 10.07.2020 | Accepted: 18.07.2020 | Published: 21.07 .2020

*Corresponding author: Dr. Pallavi Saxena

\section{Abstract}

Background: Multiple myeloma is the majorly occurring plasma cell dyscrasia. It involves the plasma cells, bone marrow and kidneys. There is monoclonal proliferation of plasma cells which secrete light chain immunoglobulins IgG type. These immunoglobulins tend to precipitate in the form of para proteins. It has a very complex pathogenesis which makes difficult to predict the prognosis of the disease. Therefore, majority of cases go into phase of relapse or progression and may sometimes present with bone lesions which were not present in the primary disease. Case Report: A 52 year male patient presented to the out patient department of our institute. He was a known case of multiple myeloma and was in the remission phase. He complained of pain in 46 and 47 region which he had undergone extraction 3 months back. On evaluation, the lesions were found to be bone lesions present in multiple myeloma. Therefore, a diagnosis of relapse case of multiple myeloma was given. Conclusion: Multiple myeloma is a disease of variable prognosis and needs to have thorough follow up protocols and an interdepartmental approach, in order to have an early diagnosis and treatment.

Keywords: Multiple myeloma, Refractory, Mandibular lesions, Bence Jones Proteins.

Copyright @ 2020: This is an open-access article distributed under the terms of the Creative Commons Attribution license which permits unrestricted use, distribution, and reproduction in any medium for non-commercial use (NonCommercial, or CC-BY-NC) provided the original author and source are credited.

\section{BACKGROUND}

Multiple myeloma (MM) is a member of the plasma cell dyscrasia group. It is a malignant neoplasm of involving the abnormal proliferation of the terminally differentiated plasma cells and also hyper secretion of immunoglobulins. The light chain component of these immunoglobulins mostly secreted in the urine in the form of para protein in the urine called the Bence Jones protiens [1]. This malignancy also affects the functioning of multiple organs like the kidneys, bone marrow and the skin [2]. Among all the plasma cell dyscrasia MM accounts about $65 \%$ [3].

MM is complex malignancy involving the interaction between the malignant progenitor cells, bone marrow stromal cells and bone marrow micro environment [4]. This pathobiology decides the treatment outcome of the disease. These processes involve many biomolecules like IL-6, TNF- $\alpha$ etc. These attributes are known to cause reduced survival rates and/or relapse or refracttory disease [5]. There are many studies suggesting that MM case have shown a durable complete remission but because of this complex pathobiology MM still remains incurable in many cases.
MM is known to be relapsing and during relapse phase it may present with any of the symptoms like variation in serum calcium levels, bone lytic lesions in mandible, or altered hemoglobin levels. Being an oral physician should be aware of the implications of such myeloproliferative disorders, on the oral cavity. Here, we encountered a case where a known MM patient who was in phase of complete remission, presented with pain in mandible post extraction which on evaluation came out to be a case of refractory or relapsed MM.

\section{CASE REPORT}

A 52 year old male patient reported to out patient department with complaint of pain in lower back jaw region since 3 months. On evaluating his medical history he was known case of MM past four years, currently in remission phase. On evaluation of his dental history it was found that he had undergone extraction of 46 and 47 one month back, at a periphery dental clinic.

On clinical examination, there was an edentulous area, in 46 and 47 region, with overlying normal alveolar mucosa and no lesion was clinically evident. An orthopantomogram was ordered which 
showed multiple solitary punched out radiolucencies in the right as well as left body region of mandible. Further radiological evaluation was done with lateral view of skull which showed which also showed similar punched out radiolucencies in the occipital region. Moreover, for detailed evaluation a postero-anterior view of pelvis was also advised which again showed similar multiple punched out radiolucent lesions.

An aspiration cytology was performed which gave a thick hemorrhagic yield and on microscopic examination of hematoxylin and eosin stained scetions showed an aggregate of plasma cells in a hemorrhagic background. Following this excisional biopsy was performed under local anaesthesia for the mandibular lesion, to have a definitive diagnosis of relapsed case of MM. For this a linear incision was made on the edentulous alveolar mucosa. This was followed by curettage of soft tissue which was blood tinged and fragile in nature. The biopsied tissue was sent for preserved in $10 \%$ neutral buffered formalin and sent for histopathology.

Histopathological evaluation of hematoxylin and eosin stained sections showed closely packed sheets of closely packed cells resembling plasma cells. These cells had round to ovoid shaped nuclei, which was eccentrically placed. Moreover, the chromatin material was clumped in the form of "cartwheel" pattern. Furthermore, laboratory investigations showed Mprotein (IgG immunoglobulin) on serum and urine electrophoresis. A slight raise in the albumin globulin ratio was also noted. Serum electrophoresis showed raised $\beta$-globulin. Serum levels of calcium were found to be as low as $5.64 \mathrm{mg} / \mathrm{dl}$.

So a final diagnosis of multiple myeloma was given, based on the widespread lesions present in the skull and also pelvis region, laboratory analysis and histopathological evaluation of the jaw lesion. The patient was referred to hemato-oncology department for further evaluation and commencement of the treatment accordingly.

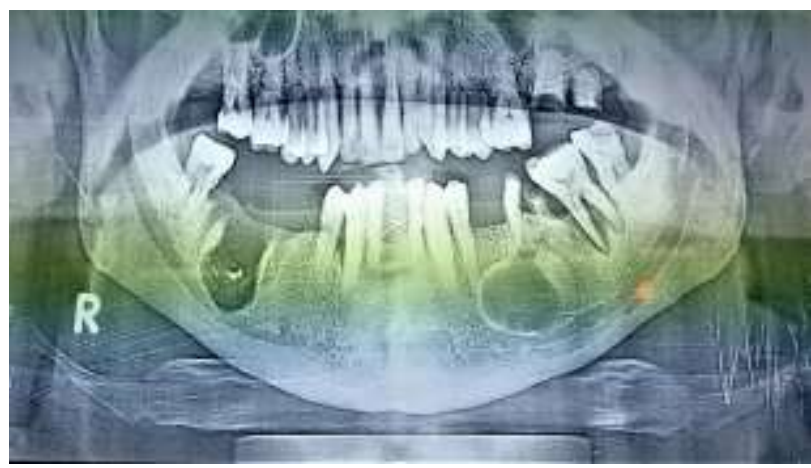

An orthopantomograph revealed presence of multiple punched out radiolucent lesions.

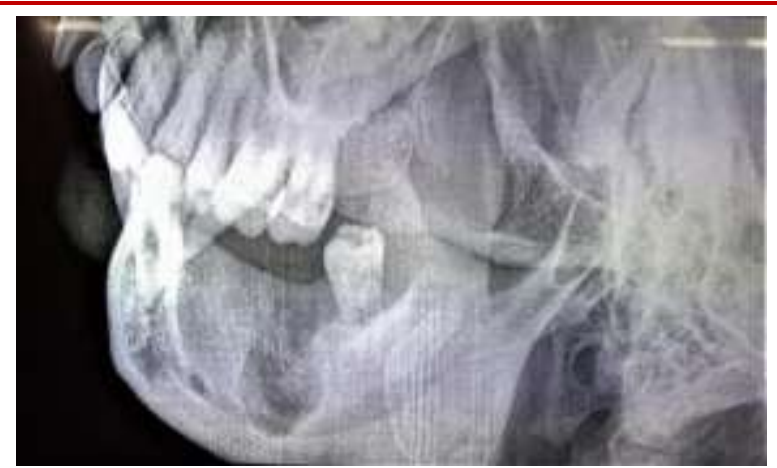

The lateral oblique view of mandible right side showed missing 46 and 47 along with a punched out lesion.

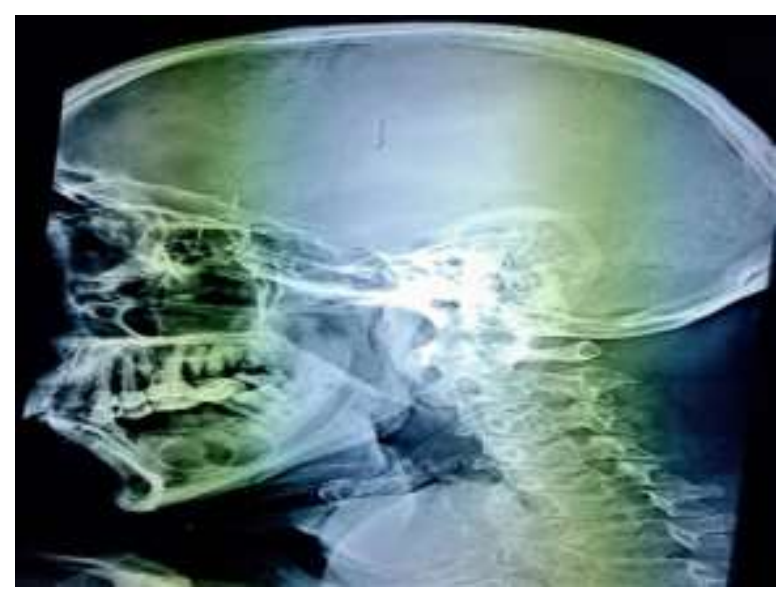

The lateral skul view showed similar punched out radiolucencies on the occipital region

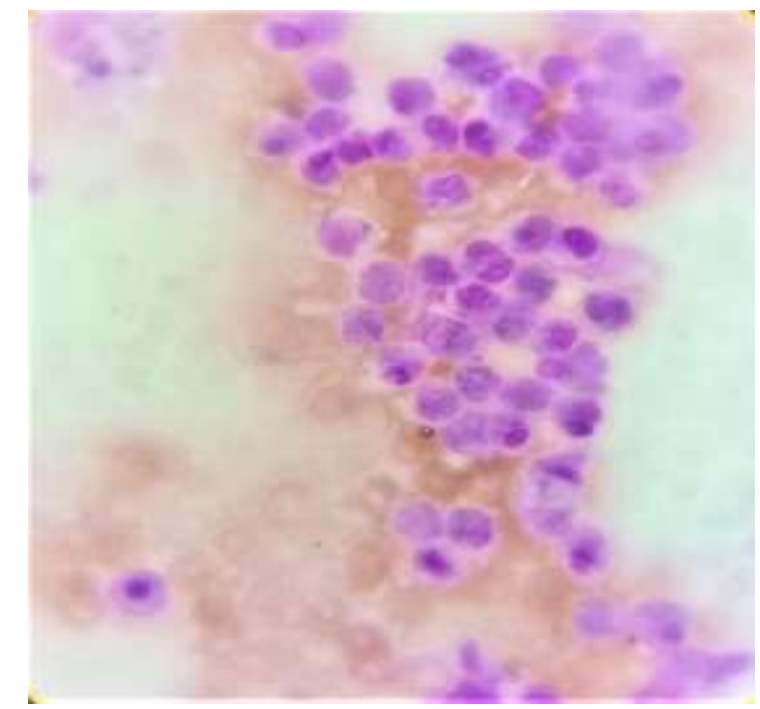

The aspiration cytology showed presence of aggregates of plasma cells in a hemorrhagic background. 
Pallavi Saxena et al; Saudi J Oral Dent Res, July, 2020; 5(7): 347-350

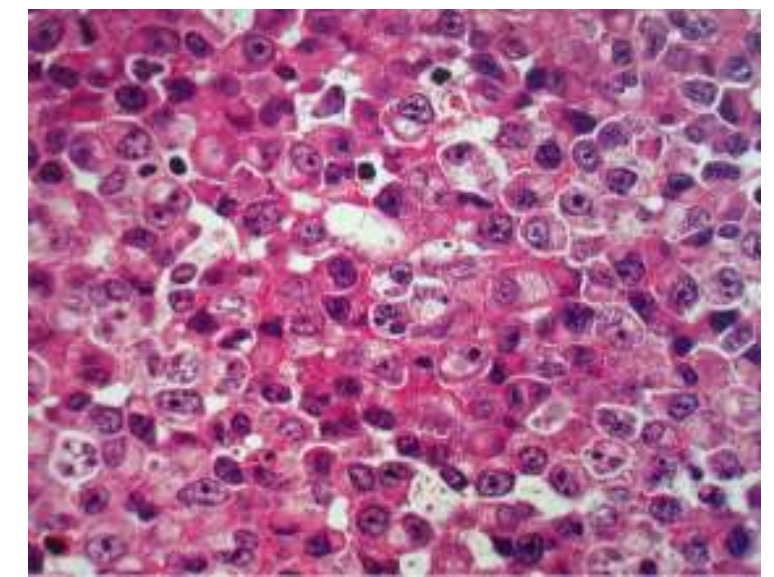

Hematoxylin and eosin stained sections showed closely packed sheets of closely packed cells resembling plasma cells. These cells had round to ovoid shaped nuclei, which was eccentrically placed.

Moreover, the chromatin material was clumped in the form of "cartwheel" pattern

\section{DISCUSSION}

MM was first described by Otto Kahler in the year 1889, therefore also called as Kahler disease. It is seen in age group of $4^{\text {th }}$ to $6^{\text {th }}$ decade, commonly found in males [6]. Our case shows accordance with this fact. Furthermore, the etiological factors of MM inlcude exposure to radiations, pesticides and previous radiotherapeutic treatment for conditions like ankylosing spondylitis [7]. In our case, the patient was farmer by occupation who had constant exposure to pesticides.

$\mathrm{MM}$ is a malignant neoplasm that involves monoclonal plasma cells, which secrete immunoglobulins [8]. In our case the serum and urine electrophoresis showed raised M-protien which is a type of $\mathrm{IgG}$ immunoglobulin. These immunoglobulins were $\mathrm{k}$ light chain type and raised upto $32.8 \mathrm{mg} / \mathrm{L}$. The diagnosis of MM is based on the CRAB criteria which includes (altered calcium levels, renal insufficiency, anaemia and bone lesions) [9]. In our case, the patient had reduced calcium levels, signs of renal insufficiency and also presence of bone lesions. $\mathrm{MM}$ is a heterogenous disease clinically as well a pathobiologically, these factors are responisble for the treatment outcome and disease relapse and progression [10]. In our case the patient was diagnosed with MM four years ago, was treated with long term administration of lenalidomide/dexamethasone and was under follow up, since past two years.

Even though the oral cavity remains a prominent site for the presentation of $\mathrm{MM}$, oral cavity involvement in $\mathrm{MM}$ ranges from $8-15 \%$. This percentage is low because of one very important reason that is being deficient medical recording [11]. In our case, the patient underwent extraction of 46 and 47, but kept on experiencing pain in the extraction site for nearly 2-3 months with no appear ant clinical lesion, a thorough documentation of the oral cavity symptoms of pain would have lead to an earlier diagnosis and commencement of treatment. Therefore, it is very important to have a very close surveillance of any oral symptoms in known MM cases.

\section{CONCLUSION}

MM is a neoplasm of nearly poor prognosis Because of the variability in the pathogenesis, MM does not follow a fixed pattern in every patient. Therefore, every patient responds differently to the treatment and may either go in complete remission or refractory/relapse phase. Hence, it requires a meticulous follow up of the treated cases. Along with this there is requirement of a multidisciplinary approach involving the dental fraternity for examination of the oral cavity, leading to an earlier diagnosis and hence timely commencement of treatment.

\section{REFERENCES}

1. Kyle, R. A., Gertz, M. A., Witzig, T. E., Lust, J. A., Lacy, M. Q., Dispenzieri, A., ... \& Plevak, M. E. (2003, January). Review of 1027 patients with newly diagnosed multiple myeloma. In Mayo Clinic Proceedings (Vol. 78, No. 1, pp. 21-33). Elsevier.

2. Liebross, R. H., Ha, C. S., Cox, J. D., Weber, D., Delasalle, K., \& Alexanian, R. (1998). Solitary bone plasmacytoma: outcome and prognostic factors following radiotherapy. International Journal of Radiation Oncology* Biology* Physics, 41(5), 1063-1067.

3. Elias, H. G., Scott, J., Metheny, L., \& Quereshy, F. A. (2009). Multiple myeloma presenting as mandibular ill-defined radiolucent lesion with numb chin syndrome: a case report. Journal of oral and maxillofacial surgery, 67(9), 1991-1996.

4. Neville, B. W., Damm, D. D., Allen, C. M., \& Bouquot, J. E. (2002). Hematologic disorders. In: Neville, B. W., Damm, D. D, Allen, C. M., \& Bouquot, J. E., editors. Oral and Maxillofacial Pathology. 2nd ed. New Delhi, India: Elsevier; 526-527.

5. Pratt, G. (2002). Molecular aspects of multiple myeloma. Molecular Pathology, 55(5), 273. -283.

6. Baykul, T., Aydin, U., \& O Carroll, M. K. (2004). Unusual combination of presenting features in multiple Radiology, 33(6), 413-419.

7. Anderson, K. C., Kyle, R. A., Rajkumar, S. V., Stewart, A. K., Weber, D., \& Richardson, P. A. S. H. (2008). Clinically relevant end points and new drug approvals for myeloma. Leukemia,22(2), 231-239.

8. Seoane, J., Aguirre-Urizar, J. M., Esparza-Gómez, G., Suárez-Cunqueiro, M., Campos-Trapero, J., \& Pomareda, M. (2003). The spectrum of plasma cell neoplasia in oral pathology. Medicina oral: organo oficial de la Sociedad Espanola de 
Pallavi Saxena et al; Saudi J Oral Dent Res, July, 2020; 5(7): 347-350

Medicina Oral y de la Academia Iberoamericana de Patologia y Medicina Bucal, 8(4), 269-280.

9. Gerecke, C., Fuhrmann, S., Strifler, S., SchmidtHieber, M., Einsele, H., \& Knop, S. (2016). The diagnosis and treatment of multiple myeloma. Deutsches Ärzteblatt International, 113(27-28), 470-476.

10. Lae, M. E., Vencio, E. F., Inwards, C. Y., Unni, K. K., \& Nascimento, A. G. (2003). Myeloma of the jaw bones: a clinicopathologic study of 33 cases. Head \& Neck: Journal for the Sciences and Specialties of the Head and Neck, 25(5), 373-381.

11. Cardoso, R. C., Gerngross, P. J., Hofstede, T. M., Weber, D. M., \& Chambers, M. S. (2014). The multiple oral presentations of multiple myeloma. Supportive Care in Cancer, 22(1), 259267. 